\title{
Transforming Cars into Computers: Interdisciplinary Opportunities for $\mathrm{HCl}$
}

\author{
Grace Eden \\ Manchester Metropolitan University \\ Manchester, United Kingdom \\ g.eden@mmu.ac.uk
}

\begin{abstract}
Road and highway infrastructures are being transformed in anticipation of self-driving vehicles. During the transition to fully autonomous road networks people and driverless cars will interact with each other in mixed traffic situations. Vehicles are currently equipped with two types of communication devices one auditory (a horn) and the other visual (signalling lights). In many instances, human drivers use these devices in combination with embodied interaction such as eye contact and gesture when communicating with other road users. Hence, horn and signalling devices currently in use may not be enough to communicate with others in traffic settings; especially when driverless vehicles become responsible for the main driving activity. Driverless vehicles require new interaction types that support Human-AV interaction in an easy to understand and intuitive way. With the transformation of cars into computers new opportunities for research present themselves to the $\mathrm{HCl}$ community.
\end{abstract}

Autonomous vehicles, Human-AV interaction, User experience, $\mathrm{HCl}$ research

\section{INTRODUCTION}

Autonomous Vehicle (AV) research and development is receiving a high-level attention both in industry and academia. Since 2014 the UK government has invested over $£ 100$ million in future transportation (UKCAVS, 2017). Whilst much of the research in this area has been dedicated to tackling technical issues such as vehicle-to-vehicle and vehicle-to-infrastructure communication there has been less research that examines the interactions between AVs and other road users such as cyclists, pedestrians, and human drivers (Parkin et al 2016).

During the transition to fully autonomous road networks many of the norms and expectations of behaviour that road users have come to rely upon may be challenged. This is especially true in situations where road users negotiate with each other. For instance, when a pedestrian moves forward to cross the road; how will an AV indicate that it was seen them and that it will stop for the person to cross? Or when a driverless vehicle prepares to move across an intersection; how will it initate, maintain, and finalise a negotiation process with a human driver?

In sociology, anthropology, and psychology investigations in transportation studies have been undertaken as early as the 1940s (Pooley et al, 2005). In sociology and anthropology, some mobilities research has focused on the micro- analysis of interaction between people, travel and transportation (D'Andrea et al, 2011) with investigations of real-time behaviour and communication practices between road users in real-world settings. In psychology, human factors research has focused on understanding driver perception, motors skills and fatigue.

With an increase in driverless vehicle research, these disciplines have taken up investigations of Human-AV interaction. In psychology, the focus is primarily on driver attention and distraction, skill degradation, motion sickness and other types of cognitive, motor, and perceptual aspects (Merat et al 2018; Cunningham \& Regan, 2015); and in sociology and anthropology the focus has been on understanding norms of conduct between pedestrians and vehicles as a source for design ideas (Vinkhuyzen \& Cefkin).

More recently, $\mathrm{HCl}$ researchers have initiated research in Human-AV interaction. This includes a traditional psychological-orientation that examines driver-vehicle interaction, dashboard design, and incar interaction (Meschtscherjakov et al, 2016); and sociological-orientations that focus on how drivers and other road users communicate with, anticipate the intentions, and interpret the behaviour of AVs (Brown \& Laurier, 2017; Eden et al, 2017). Drawing upon the skills held within the $\mathrm{HCl}$ community, researchers are uniquely positioned to participate in 
the design of novel interfaces that support intuitive Human-AV interactions.

\section{CONVERGENCE OF CARS AND COMPUTERS}

The software industry is increasingly moving into the automotive sector. As a result, there has been a shift in customer preferences. For instance, when shopping for vehicles many customers are more interested in dashboard displays, autonomy and connectivity rather than the details of the chassis and engine design (Beiker et al, 2016). As technology companies enter the automotive market vehicles are slowly being transformed into 'computers on wheels' (ibid).

Computerised vehicles require entirely new interfaces to display information to users - new computer interfaces. This requirement places the $\mathrm{HCl}$ community in a unique position to contribute to research and development in this area. Developing links with both the mobilities and human factors research communities is worth exploring. Especially when seeking funding for new research projects in Human-AV interaction. Initiating cross-disciplinary collaborations could begin by hosting a series of workshops to scope out how each research community could complement the other's work and to identify synergies. With each having its different focus:

- Human factors - how humans use machines;

- Mobilities - how and why people travel;

- Human-computer interaction - how humans use computers

Working together to investigate the interrelationship between machines, computers and travel these three research disciplines could work together to develop a multi-layered and more complete understanding of interactions between vehicles and humans. As a result, we could make significant contributions to our understanding of Human-AV interaction and improve the design of next generation AV interfaces.

\section{DESIGNING AV-HUMAN INTERACTIONS}

Considering future transportation scenarios, it is essential that road users have the ability to easily understand and interpret AV communication. This includes its situational awareness in a given moment and its planned trajectory of movement. For instance, people who interact with AVs need to know if it intends to give way to another driver so that it can pass; how it communicates to a cyclist riding beside it, how it indicates to a pedestrian that it 'sees' them or communicates its intention to stop so that a person can safely cross the road.
Before people eventually encounter $\mathrm{AVs}$ in realworld traffic situations we need to design, prototype and evaluate a variety of communication devices in different traffic scenarios such as intersections, overtaking, pedestrian crossing and cyclist movement. Each traffic scenario may require different interface types, for instance:

- Gesture - interfaces that display that an AV recognises and distinguishes between gestures such as holding up a hand to indicate stop; waving forward to indicate that another road user is giving an $\mathrm{AV}$ the right of way; or a wave for saying 'thank you'.

- Sound - Electric AVs are quiet and so do not provide the expected auditory cues to recognise that a vehicle may be behind a road user. Research is needed to investigate new communication mechanisms that provide new auditory cues. This type of interaction could be important for pedestrians and cyclists.

- Lights - Rather than using one language (e.g. English, French, German) over another to communicate, research is needed to investigate larger and more obvious lighting systems that could be positioned on the body of a vehicle to communicate the intentions of an AV to turn, pass or stop for example.

- Icons - These may be more of a challenge to design because pictograms may not always be easily interpreted. Research is needed to understand how current international traffic icons and newly designed icons might be displayed in Human-AV traffic encounters.

The design, prototyping, and evaluation of interfaces is the cornerstone of $\mathrm{HCl}$ research. In addition, $\mathrm{HCl}$ research focuses on understanding how interfaces support the social norms and expectations of people in a particular setting. In Human-AV interaction, designs need to be evaluated for how effectively they align with these, such as:

- Recognition - Design for communication that an AV has seen other road users and is taking that into account when planning its near-term trajectory.

- Intention - Displaying to other road users its planned movement on a path such as moving forward, stopping, turning, acceleration, or over-taking.

- Negotiation - Design for more sustained short-term interaction with other road users to initiate, maintain and finalise transactions with humans at intersections and in other situations where sustained communication may be required. 
These are a few examples of how we might begin to frame a programme for the $\mathrm{HCl}$ research community to become a major contributor to the autonomous vehicle research and development agenda. Especially since these 'computers on wheels' will interact with people in situations where they will need to communicate through some type of interface with other road users.

\section{CONCLUSION}

Coordinating orderly traffic flows is a complex social activity where people communicate, negotiate, and anticipate the next moves of other road users. What is typically regarded as routine interaction between people becomes potentially problematic for a fully autonomous vehicle with no attentive human driver. A recent UK government report forecasts that the introduction of Connected and Autonomous Vehicles (CAVs) will have a significant impact on future mobility (Highways England, 2017). Developing Human-AV interactions that are easy to recognise and understand is essential for increasing public trust and acceptance of AVs. The design, prototype and evaluation of new interfaces for Human-AV interaction could benefit from the expertise of multiple research disciplines from ergonomics, anthropology, psychology, mobilities and $\mathrm{HCl}$ engaging in interdisciplinary research.

\section{REFERENCES}

Beiker, S., Hansson, F., Suneson, A., Uhl, M. (2016) How the convergence of automotive and tech will create a new ecosystem, McKinsey. https://www.mckinsey.com/industries/automotiveand-assembly/our-insights/how-the-convergenceof-automotive-and-tech-will-create-a-newecosystem (retrieved 17 March 2018).

Brown, B, \& Laurier, E. (2017) The Trouble with Autopilots: Assisted and Autonomous Driving on the Social Road. In Proceedings of the SIGCHI Conference on Human Factors in Computing Systems (CHI'17), 416-429.

Cunningham, M. \& Regan, M.A. (2015) Autonomous vehicles: Human factors issues and future research. In Australasian Road Safety Conference (ARSC 2015), Gold Coast, Australia, 14-16 October 2015.

D'Andrea, A. Ciolfi, L. \& Gray, B. (2011) Methodological Challenges and Innovations in Mobilities Research, Mobilities, 6:2, 149-160, http://dx.doi.org/10.1080/17450101.2011.552769

Eden, G., Nanchen, B., Ramseyer, R., and Evéquoz, F. (2017) On the Road with an Autonomous Passenger Shuttle: Integration in Public Spaces. In SIGCHI Conference on Human Factors in Computing Systems, Denver CO, New York:
ACM Press, pp. 1569-1576. http://dx.doi.org/10.1145/3027063.3053126

Merat N., Louw T., Madigan R., Wilbrink M., Schieben A. (2018) What externally presented information do VRUs require when interacting with fully Automated Road Transport Systems in shared space? Accident Analysis \& Prevention.

Meschtscherjakov, A., Tscheligi, M., Szostak, D., Krome, S., Ratan, R., Pfleging, B., Politis, I., Baltodan, S., Miller, D., Ju, W. (2016) HCl and Autonomous Vehicles: Contextual Experience Informs Design. Workshop Summary, In Proceedings $\mathrm{CHI}$ Conference Extended Abstracts on Human Factors in Computing Systems (CHI '16),3542-3549.

http://doi.acm.org/10.1145/2851581.2856489

Parkin, J., Clark, B., Clayton, W., Ricci, M. and Parkhurst, G. (2016) Understanding interactions between autonomous vehicles and other road users: A literature review. Technical Report. University of the West of England, Bristol. http://eprints.uwe.ac.uk/29153 (retrieved 16 March 2018).

Pooley, C., Turnbull, J., Adams, M. (2005) A mobile century?: changes in everyday mobility in Britain in the twentieth century. Ashgate.

SAE (Society of Automotive Engineers) (2016) Taxonomy and Definitions for Terms Related to Driving Automation Systems for On-Road Motor Vehicles. http://standards.sae.org/j3016_201609 (retrieved 16 March 2018).

Highways England (2017), Strategic Road Network InitialReport.https://www.gov.uk/government/publi cations/highways-englands-strategic-roadnetwork-initial-report (retrieved 14 March 2018).

UKCAVS (2017) UK Connected and Autonomous Vehicle Research and Development Projects 2017.

https://www.gov.uk/government/publications/conn ected-and-autonomous-vehicle-research-anddevelopment-projects-2017 (retrieved 27 March 2018)

Vinkhuyzen, E. \& Cefkin, M.. (2016) Developing Socially Acceptable Autonomous Vehicles. In Proceedings of Ethnographic Praxis in Industry Conference (EPIC '16), 522-534. doi:10.1111/1559-8918.2016.01108 